\begin{tabular}{|l|l|l||}
\hline \multicolumn{2}{|c|}{ PublisherInfo } \\
\hline \hline PublisherName & $:$ & BioMed Central \\
\hline \hline PublisherLocation & $:$ & London \\
\hline \hline PublisherImprintName & $:$ & BioMed Central \\
\hline \hline
\end{tabular}

\title{
Evolution without sex
}

\begin{tabular}{|l|l|l||}
\hline \multicolumn{2}{|c||}{ ArticleInfo } \\
\hline \hline ArticleID & $:$ & 3650 \\
\hline \hline ArticleDOI & $:$ & $10.1186 /$ gb-2000-1-3-reports0068 \\
\hline \hline ArticleCitationID & $:$ & reports0068 \\
\hline \hline ArticleSequenceNumber & $:$ & 19 \\
\hline \hline ArticleCategory & $:$ & Paper report \\
\hline \hline ArticleFirstPage & $:$ & 1 \\
\hline \hline ArticleLastPage & $:$ & 4 \\
\hline \hline & & RegistrationDate : 2000-8-24 \\
ArticleHistory & $:$ & Received $\quad$ 2000-8-24 \\
& & OnlineDate $\quad 2000-9-18$ \\
\hline \hline ArticleCopyright & $:$ & BioMed Central Ltd2000 \\
\hline \hline ArticleGrants & $:$ & \\
\hline \hline
\end{tabular}




\begin{tabular}{|l|l|l||}
\hline ArticleContext & $:$ & 130591133 \\
\hline
\end{tabular}

\section{James Cotton}

\section{Abstract}

Genome structure confirms the chastity of some ancient asexuals.

\section{Significance and context}

In most animal and plant species - where males make very little or no investment in individual young - an asexual female could have twice as many grandchildren as her sexual relatives. Explaining why sexual reproduction persists in a wide spectrum of living things despite this enormous short-term cost is perhaps the most difficult problem in evolutionary biology. Predictably, many different hypotheses have been put forward to explain the prevalence of sexual reproduction, and a great deal of theoretical and empirical work focuses on the question. There are many exclusively asexual eukaryotes, however, and those that seem to have persisted without sex over long periods of time represent an important test for many hypotheses to explain the prevalence of sex. The bdelloid rotifers, a group of fresh-water and damp-habitat dwelling microscopic metazoan invertebrates, have become the best known candidates for 'ancient asexuals'. No males, hermaphrodites or evidence of meiosis has been discovered in any of the 360 or so described species, and the bdelloid fossil record stretches back to 35 million year old Dominican amber. It is this notoriety as a persistent and successful asexual lineage that has led to the bdelloid rotifers being called 'something of an evolutionary scandal'. Welch and Meselson present direct molecular evidence that bdelloids have truly persisted over a very long time period without recombination, in an important counter to the many theoreticians who have doubted the existence of truly asexual ancient lineages.

\section{Key results}

The cycle of meiosis and syngamy observed in the vast majority of eukaryotes prevents alleles from accumulating any great number of mutations independent from one another, as mutations will become either fixed or extinct as a result of genetic drift. Welch and Meselson have realized that, in a completely asexual organism in which meiotic recombination has ceased, this relationship will break down, allowing formerly allelic sequences to diverge as they effectively become distinct, haploid loci. Very little recombination should be necessary to maintain an allelic relationship, so observing a greater degree of diversity between such loci in a single individual than between the same loci in two related species would be powerful evidence that the organisms have been evolving asexually since before the species' 
common ancestor. Welch and Meselson measured substitutional changes at selectively neutral sites in four genes from four species of bdelloids, and found exactly this pattern of extreme divergence between former alleles. They were especially careful to use multiple PCR reactions and to clone many molecules from each reaction, to ensure that all copies of these genes were sampled. This allowed them to show that, for two of the genes, existing copies form two distinct lineages in the asexual bdelloids, presumably descended from the alleles of a diploid sexual ancestor.

\section{Links}

A perspective article (Judson and Normark Science 2000, 288:1185-1186) commenting on Welch and Meselson's finding appeared in the same issue of Science and is available to subscribers.

\section{Conclusions}

Bdelloid rotifers have uniquely strange genomes, differing completely from obligately or facultatively sexual rotifers. The lack of allele pairs on homologous chromosomes excludes the possibility that bdelloid rotifers are ordinary diploids engaging in very rare or cryptic sex. A few exotic possibilities remain that could produce this pattern in a sexual species - for example, an ancestral genome duplication in a lineage with haploid females - but it seems fairly certain that bdelloid rotifers are exactly what they appear to be: a successful and ancient group of entirely asexual metazoans.

\section{Reporter's comments}

Much future work must focus on the bdelloids themselves. Further confirmation of the bdelloid's asexuality would come from cytological evidence that the chromosomes of these organisms no longer form homologous pairs, but the truly exciting work will be to examine how well competing theories about the maintenance of sex fit the case of the bdelloids. If bdelloids have particularly low or high mutation rates, enjoy particularly low parasite loads or show unusually high dispersal, these facts will help to differentiate between competing ideas. Using Welch and Meselson's technique to confirm the status of other asexual lineages will strengthen comparative tests between competing theoretical models. Welch and Meselson's findings also suggest some interesting genetic consequences of a switch away from sexuality. Some of the benefit of asexuality in the bdelloids could result from the opportunity for effectively duplicated genes to evolve new functions, and shuffling of these duplicates could have created local homology regions where localized mitotic recombination can occur. These sorts of genomic effects could increase the 'cost of sex' in some asexuals, and so tip the evolutionary balance away from sexual reproduction. Bdelloid rotifers now become the group of choice for workers seeking 
to explain how asexual lineages can persist, and should help explain why frequent sexual reproduction is the reproductive system of choice for so many living things.

\section{Table of links}

Science

Judson and Normark Science 2000, 288:1185-1186

\section{References}

1. Welch DM, Meselson M: Evidence for the evolution of bdelloid rotifers without sexual reproduction or genetic exchange. Science. 2000, 288: 1211-1215. 0036-8075 